\title{
The Urban Heat Island of Dublin City
}

\author{
John Sweeney \\ Department of Geography \\ St. Patrick's College, \\ Maynooth, \\ Co. Kildare
}

\begin{abstract}
Automobile traverses revealed an intense urban heat island in Dublin city during winter nights with light winds and clear skies. Urban rural contrasts of over $6.5^{\circ} \mathrm{C}$ may be anticipated, and a close correspondence between building density and temperature exists. The city's location close to warm sea and cold uplands appears to be responsible for the generation of active mesoscale air movement during such nights. These circulations bring both cold mountain air into the southern suburbs and warmer oceanic air into the eastern fringes and are responsible for creating substantial variations in temperature within the urban area itself. Cold air drainage along surprisingly gentle slopes occurs, channelled along the valleys of small streams particularly in the south of the city. Considerable intra-urban differences in aggregate energy demand may be anticipated as a consequence.
\end{abstract}

Key index words: Urban temperatures, climate, Dublin, Ireland.

\section{Introduction}

The urban heat island is a reflection of the totality of microclimatic changes instigated by urbanisation. For it is the transformation of land use, the replacement of natural surfaces by those characteristic of a city, which so radically alters the aerodynamic, radiative, thermal and moisture properties of urban areas. The precise manner in which these changes combine to create a unique urban microclimate for each town or city is not yet fully understood. Possibe causes include: (1) the increased counter-radiation from the urban pollution 'dome'; (2) the trapping of long-wave radiation beneath the urban 'canopy'; (3) the high thermal admittance of concrete, brick and asphalt; (4) the reduction of evapotranspiring surfaces; (5) the trapping of heat due to air stagnation in the urban 'canyons'; and (6) the release of anthropogenic heat. All these factors contribute to making urban areas, on occasions, significantly warmer than the surrounding countryside.

This excess in temperature was first discovered by Howard (1833) for a London he described as "this volcano of a thousand mouths". An average nocturnal excess of $2^{\circ} \mathrm{C}$ was measured, a value which might be inferred from more recent studies, (Chandler, 1976), to be fairly typical of large cities in the mid-latitudes. A

Irish Geography 20 (1987) 1-10, 0075-0778/87/\$03.50 (C) Geographical Society of Ireland, Dublin. few decades after Howard, radiative cooling of the rural environs was identified as the condition maximising these temperature contrasts (Renou, 1855), and since then much work has been done in a great many of the world's cities on the causes and structure of urban heat islands, and their responses to different meteorological conditions (Landsberg, 1981). This explosion of interest is clearly related to the accelerating pace of world urbanisation, a phenomenon which will place over $50 \%$ of mankind in urban centres within the next decade.

Though the existence of an urban heat island for Dublin city is evident in temperature records (Irish Meteorological Service, 1983), it has not been studied in detail. It is the purpose of the present study to examine the intensity and morphology of Dublin's heat island under different conditions, particularly to assess its role in air pollution diffusion (Nkemdirim et al, 1975; Bennett and Saab, 1982).

\section{General Characteristics and Controls}

The mean intensity of the Dublin urban heat island is $1.2^{\circ} \mathrm{C}$ (Fig. 1). Although little seasonal variation is apparent, there is a slight tendency for a summer maximum, a feature common to most U.K. and west coast North American cities (Chandler, 1978). That the heat island effect is actually slightly stronger outwith the winter heating season implies that anthropogenic heat is only a partial cause, and that the urban effect on the radiation balance is a complex, multi-faceted, influence. 


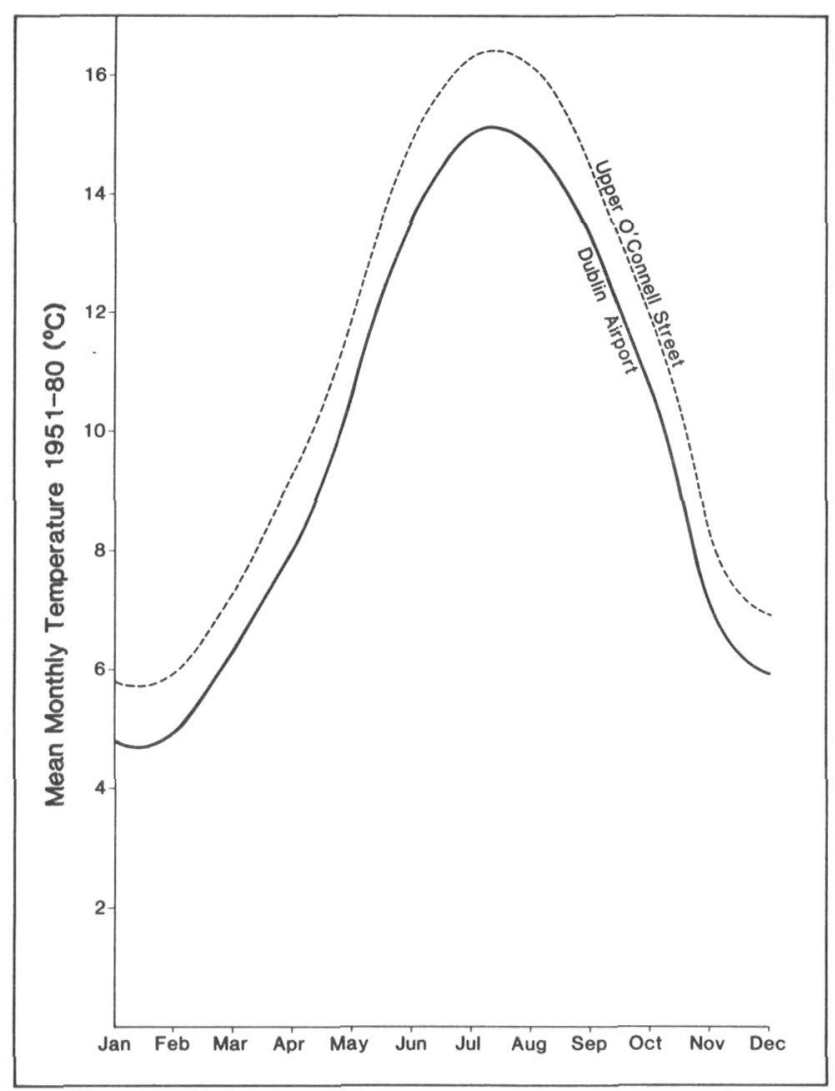

Figure 1 Mean Monthly Temperatures at Dublin Airport and Upper O'Connell Street 1951-1980.

An energy balance for a city may be written as follows:

$$
\underset{\substack{\text { Radiant } \\ \text { Flux }}}{\mathrm{H}_{\mathrm{r}}}+\underset{\substack{\text { Anthropogenic } \\ \text { heat flux }}}{\mathrm{H}_{\mathrm{a}}} \stackrel{\substack{\text { Sensible } \\ \text { heat flux }}}{+} \underset{\text { heat flux }}{\mathrm{H}_{\mathrm{c}}}+\underset{\text { heat flux }}{\underset{\text { heund }}{\mathrm{H}_{\mathrm{g}}}}
$$

The radiant flux can be split into short-wave and long-wave fluxes:

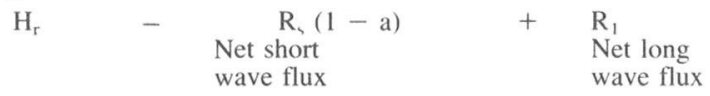

where $\mathrm{R}_{\varsigma}$ is the incoming short-wave radiation, and a is the urban albedo.

Urbanisation acts to attenuate incoming short-wave radiation, typically by about $15-20 \%$ (Bennett and Saab, 1982). This is most marked in the ultra-violet wavelengths, resulting in less sunshine in towns than in the adjacent countryside. For example, on days with high pollution, Hufty (1970) noted that Liege, in Belgium, lost 55 minutes of sunshine per day, while in the mid-1960s the inner part of London had $16 \%$ less sunshine duration than the countryside (Chandler, 1965). Following pollution abatement, many cities now have much more transparent atmospheres, and sunshine hours, especially in winter, have increased, often quite dramatically. In the case of London,

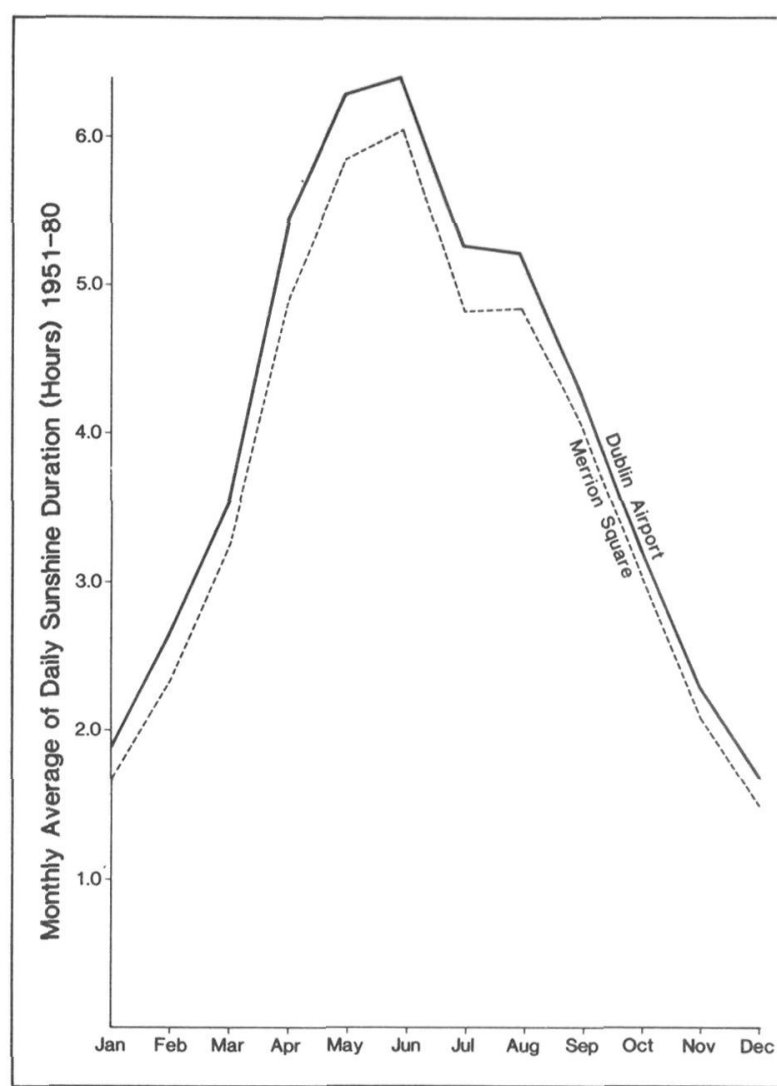

Figure 2 Mean Monthly Averages of Daily Sunshine at Dublin Airport and Merrion Square 1951-1980.

December values have increased by $70 \%$ (Jenkins, 1969). For Dublin, the effect of possessing one of the most smoke polluted atmospheres in western Europe is apparent in Fig. 2. The city loses over 116 hours of sunshine per year, about $8 \%$ of the total received at the Airport. This diminution probably occurs mostly at the low solar elevations during early morning and late evening. The anthropogenic influence is particularly well demonstrated by contrasting the slight improvement in sunshine duration in the central city during the traditional August holiday period, with the slight reduction observed at the Airport.

Some compensation for these reductions is provided by the rather lower albedo which cities possess; in the case of Dublin probably about 0.15 (Oke, 1978), as against a rural value of about 0.25 . The pollutant shield also helps to increase downward long-wave radiation (Venkatram and Viskanta, 1976), although this is partially offset at night by stronger thermal radiation from the warmer city. Overall, only a small net all-wave radiation deficit in the city is likely in comparison with rural areas.

Radiation conditions, particularly in the canyon-like streets of some inner cities, are greatly complicated by the restrictions imposed by tall buildings on horizons. 
Complex radiative interactions between building fronts act to retain heat, so that the area of the city actually radiating to the sky is only a relatively small proportion of the total surface. This restricted sky view factor was shown to correlate strongly with street temperatures by Barring et al. (1985) for Malmo in Sweden. It is probably less important in Dublin than many other cities, however, because of the relative absence of high rise buildings.

An important contributory cause of the elevated temperatures found in cities, particularly during winter, is heat emission from fuel burning. In the Manhattan area of New York, the most extreme example, heat production from combustion is 2.5 times greater in winter than solar income (Bornstein, 1968). However, most other cities cover a greater area and have considerably smaller population densities. By scaling down national energy consumption data for 1983, a conservative annual heat emission rate of 5.0 $\times 10^{16} \mathrm{~J}$ may be estimated for Dublin using the method of Garnett and Bach (1965). Comparative data for other cities are shown in Table 1. The value for Dublin also includes an estimate of $5.3 \times 10^{15} \mathrm{~J}$ for the metabolic heat production of approximately one million people and their appropriate number of domestic animals (Terjung, 1970). Overall, the anthropogenic component for Dublin is approximately $29 \%$ of total annual solar income, comparable with the 34\% found for Sheffield in 1952 by Garnett and Bach.

In summary, although urbanisation modifies every component flux of the energy balance, the net effect on urban/rural radiation differences is probably quite slight. This arises from the manner in which the input/output changes cancel each other out and implies the nocturnal heat island is a consequence primarily of the release of stored heat by the urban fabric and by anthropogenic sources. Also it must be emphasised that the contributions made by the various energy fluxes described exhibit marked seasonal and geographical variations.

\section{Detailed Characteristics of the Dublin Heat Island}

In order to examine better the detailed structure of the Dublin urban heat island, a number of automobile traverses of the city were made during winter 1983/84 on nights when good development of the phenomenon might have been expected. The instrumentation consisted of a shielded thermistor probe, about $1.5 \mathrm{~m}$ above the ground, housed in a louvred box which in turn was fixed to the roof rack of the car. A small microcomputer interrogated the thermistor at intervals of one minute and displayed the temperature on a portable monitor inside the car. Temperature values were thus obtained every minute during the traverse and the location of each reading was recorded. The arrangement was powered from the car battery. Before the surveys were carried out, a short closed traverse was conducted to determine whether heat from the car engine had any effect on the thermistor. It was found that neither variations in speed nor time had any detectable effect. The thermistor was also checked against two mercury thermometers. Furthermore, the sensitivity of the apparatus was adjusted so as not to register extremely short period fluctuations in temperature, such as those arising from engine exhausts, but at the same time to be capable of discriminating significant local differences in temperature.

Using this equipment closed traverses were made along a $150 \mathrm{~km}$ route in the Dublin area (Fig. 3). At the 1986 census this area had a population of approximately a million and encompassed $300 \mathrm{~km}^{2}$. The route was deliberately chosen to sample a variety of urban and suburban environments and usually took just under 5 hours to complete. The speed of the car was maintained as far as possible below $1 \mathrm{~ms}^{-1}$ (36 $\left.\mathrm{kmh}^{-1}\right)$. At this speed Penman and Long (1949) found good agreement with temperatures that would have been obtained in a Stevenson screen with moderate ventilation. Readings from the same location taken

TABLE 1

Anthropogenic Heat Production from Selected Cities

$\begin{array}{lcccc}\text { Urban Area } & \text { Year } & \begin{array}{c}\text { Population } \\ \left(10^{6}\right)\end{array} & \begin{array}{c}\text { Anthropogenic } \\ \text { Heat Production }\end{array} & \begin{array}{c}\text { Total Solar } \\ \text { Income } \\ \text { W m }^{-2}\end{array} \\ \text { Manhattan (New York) } & & & 117 & 93 \\ \text { Montreal } & 1967 & 1.7 & 99 & 52 \\ \text { Budapest } & 1961 & 1.1 & 43 & 46 \\ \text { Sheffield } & 1970 & 1.3 & 19 & 56 \\ \text { West Berlin } & 1952 & 0.5 & 21 & 57 \\ \text { Vancouver } & 1967 & 2.3 & 19 & 57 \\ \text { Hong Kong } & 1970 & 0.6 & 4 & 110 \\ \text { Los Angeles } & 1971 & 3.9 & 21 & 108 \\ \text { Dublin } & 1968 & 7.0 & 18 & 61\end{array}$

(Source: Oke, 1978) 


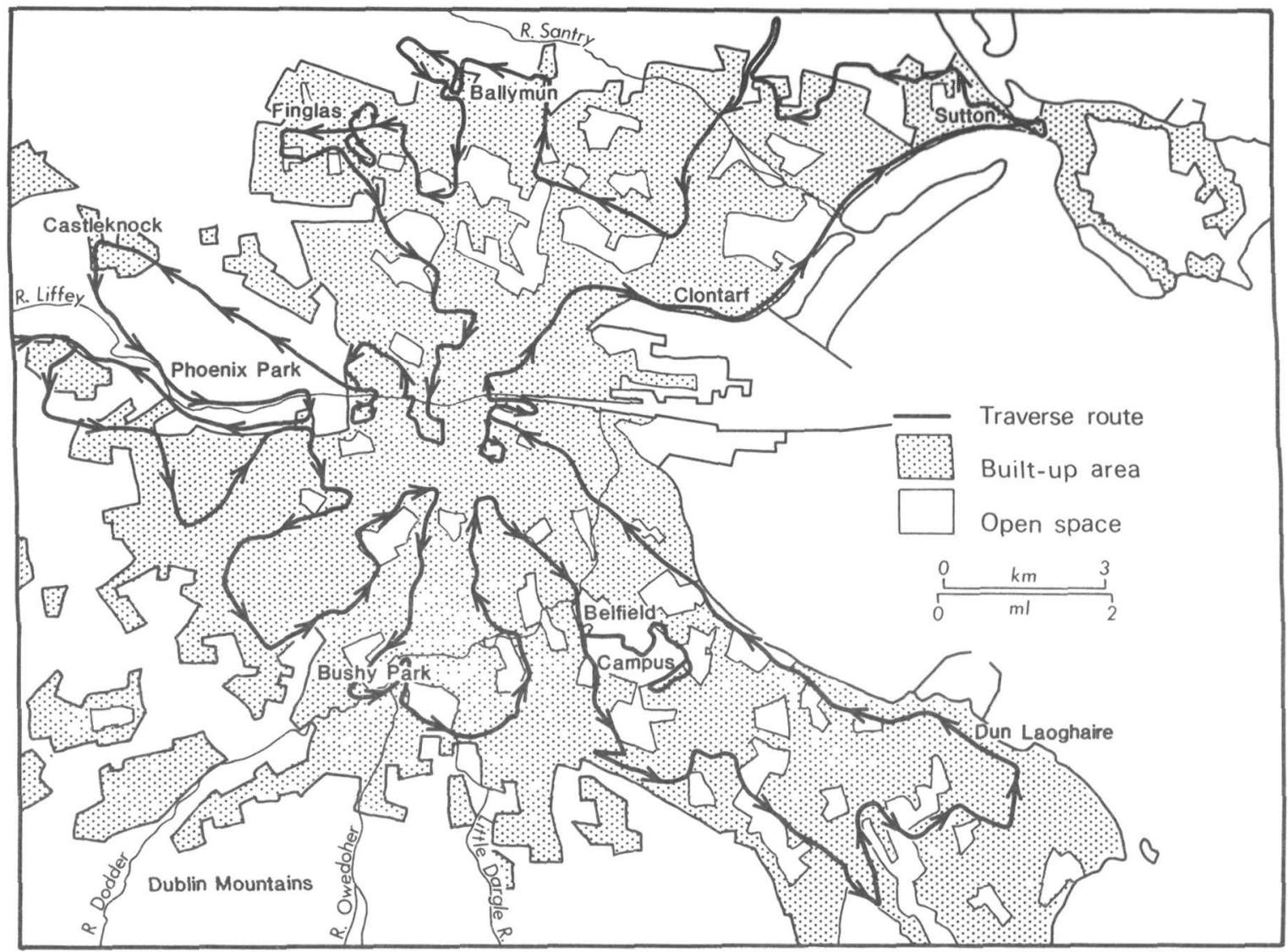

Figure 3 Traverse Routes.

more than once during the traverse enabled all temperatures to be standardised to the time of completion. A linear fall in temperature was assumed for the urban area for this purpose. In their work in Montreal and Vancouver, Oke and Maxwell (1975) found that nocturnal urban cooling followed a linear trend. A dense network of points could then be analysed to produce isotherm maps, three of which are discussed below.

\section{Night of 22/23 November 1983}

Light westerly to northwesterly winds of $2-3 \mathrm{~m} \mathrm{~s}^{-1}$ prevailed on this night, in association with an anticyclone covering Ireland. Cloud cover was 3 oktas, and widespread frost was reported; conditions conducive to good heat island development. An intense heat island was recorded resulting from a temperature of $-5^{\circ} \mathrm{C}$ existing at the urban boundary in the northwest increasing to $+1^{\circ} \mathrm{C}$ at the seafront in the north-east of the city (Fig. 4). A secondary maximum was also apparent at the city centre. Particularly in the south, a strong temperature 'cliff' can be seen, in places approaching the horizontal temperature gradient of $4^{\circ} \mathrm{C} \mathrm{km}^{-1}$, which Oke (1978) claimed as a characteristic of this zone. A much more gradual temperature gradient is apparent on the windward (northwest) side of the city. This corroborates the findings of Chandler (1961) in London where, with light winds, thermal gradients were found to be strongest on the leeward side of the city.

The influence of increasing building density towards the centre of the city is apparent in the gradual, and then pronounced, rise towards a peak of $+0.5^{\circ} \mathrm{C}$ in the central business district. However, smaller clusters of more dense settlement, and warmer temperatures, around the urban periphery are apparent, such as at Castleknock and Finglas to the west of the city. A significant secondary heat island is also detectable at the city's major high rise housing development at Ballymun. The large temperature anomaly around the Sutton tombolo is however more difficult to explain and probably relates to advection of heat from the adjacent sea. The peninsular configuration may also be instrumental in this. A smaller heat island very close to the sea is also apparent between the piers at Dun Laoghaire. 


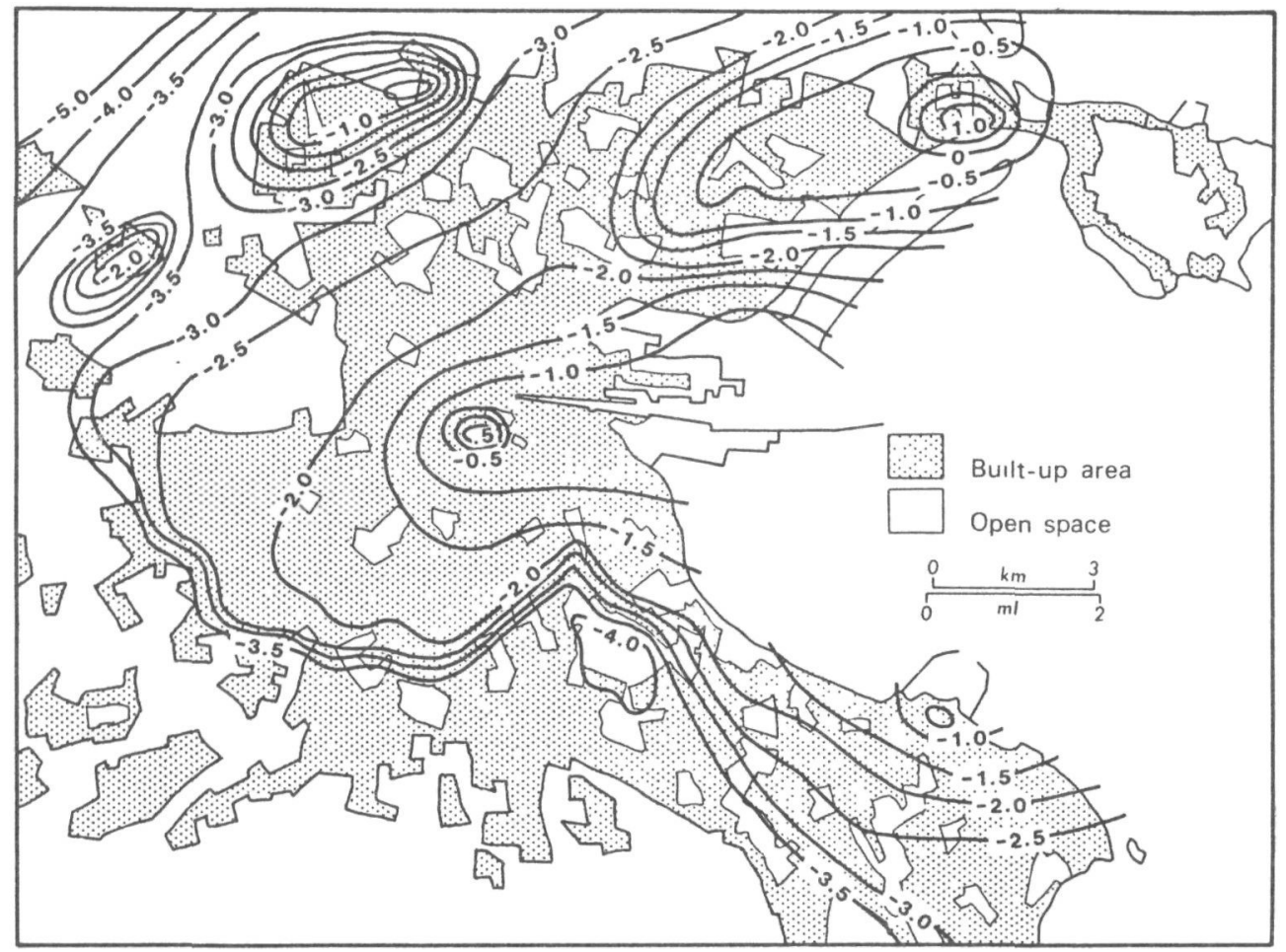

Figure 4 Temperatures in Dublin City 23.00 hrs., 22nd November 1983.

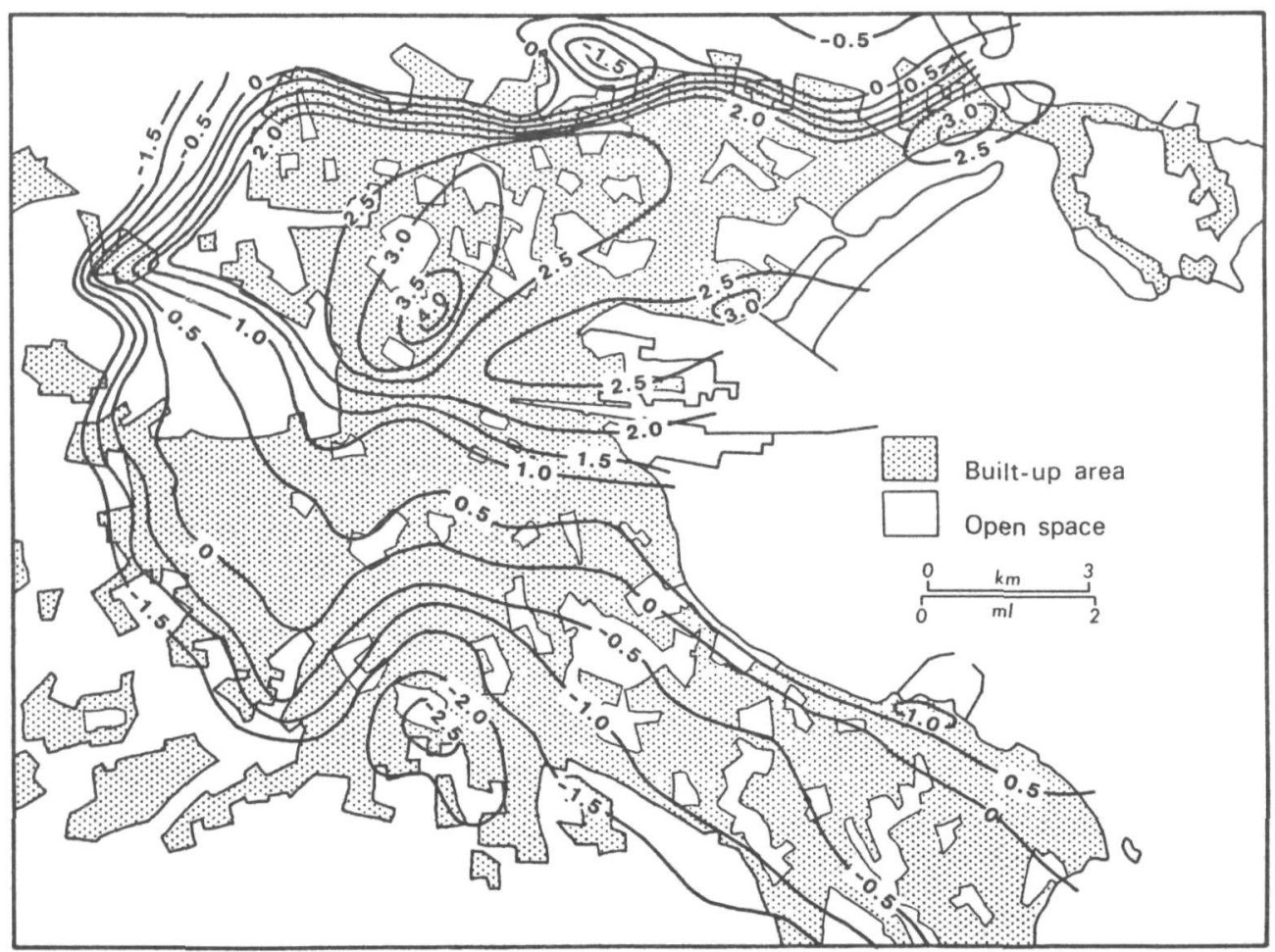

Figure 5 Temperatures in Dublin City 23.00 hrs., 14th February 1984. 
The scale of the investigation does not allow all of the smaller features to be highlighted. However, the effect of open spaces within the urban area is shown by the cold island centred over the University College campus at Belfield in the south east of the city. In the absence of significant topographical contrasts, a reduced building density is the probable cause. Thus it is surprising that the influence of Phoenix Park is not more apparent in the maintenance of a cold air wedge extending into the city centre. In a study of Christchurch, New Zealand, Napper et al. (1981) found marked cold islands in urban parks.

By far the most striking discovery of this traverse, however, was the lack of correspondence between the urban temperature 'cliff' and the built-up area to the south of the city. A displacement of the urban temperature boundary some $3 \mathrm{~km}$ into the city has evidently occurred. This may be attributed to large scale katabatic drainage of air from the Dublin Mountains which overlook the south of the city. This downward movement of air can be seen to have resulted in a long wedge of cold air moving along the valleys of the Dodder, Owedoher and Little Dargle rivers, all small right bank tributaries of the Liffey, pushing the urban air boundary north,' almost to the coast at some points. Moving westwards out of these shallow, ill-defined valleys, the isotherms again correspond tightly with the urban boundary. On this night, therefore, much of the southern city had temperatures around $-4^{\circ} \mathrm{C}$ while the northern suburbs were up to $5^{\circ} \mathrm{C}$ warmer. The consequences for demand management for electricity and gas supplies are obvious.

\section{The night of 1415 February 1984}

An anticyclone centred in the Baltic Sea maintained a strong ridge over Ireland on this occasion with light easterly and south easterly winds of $2-3 \mathrm{~m} \mathrm{~s}^{-1}$ being experienced at Dublin Airport. Cloud cover consisted of 2 oktas fractostratus and temperatures were again low. A heat island of intensity $6.5^{\circ} \mathrm{C}$ was measured (Fig. 5). As might be expected with this wind direction, the area of peak temperatures was displaced slightly towards the north-west of the city centre. In contrast to the previous example the steepest thermal gradient is now located towards the north and west of the city where excellent correspondence with the urban boundary is apparent. Again the steepest thermal gradient occurs on the leeward urban edge.

Once more the southern and south eastern fringes of the city display an apparent displacement of the isotherms towards the north, and again the likely cause relates to katabatic wind action. The traverse on this occasion was designed to give a more detailed coverage of points in this part of the city to investigate further this aspect and the results show clearly a cold core centred over Bushy Park, on the bank of the River Dodder. A counterpart to this exists on the north side of the city, just outside the temperature cliff. A small enclosed system of isotherms here is aligned along the course of the Santry river, a small channelised stream flowing into Dublin Bay. Possible advection of warmth from the Bay is also suggested by the existence of smaller warm islands within the general heat island plateau along its eastern margins, at Dun Laoghaire, Sutton and Clontarf.

Clearly, an important influence on the detailed morphology and intensity of the Dublin heat island is exerted by mesoscale air movement from both warmer and colder source areas adjacent to the city. A mechanism for these movements is suggested in the discussion below.

\section{The night of 22/23 February 1984}

Figure 6 shows the heat island on the night of February 22/23 when a depression was situated over the Irish Sea and winds of 3-6 m s ${ }^{1}$ from the north east were measured at Dublin Airport. Cloud cover was 4 oktas stratocumulus. These are conditions which militate against good heat island development, and the maximum urban-rural difference can be seen to be only $1.5^{\circ} \mathrm{C}$. A pattern of gentle thermal gradients is apparent, and the heat island is only weakly developed. This is a feature of wind speeds over $5 \mathrm{~m} \mathrm{~s}^{1}$ which Chandler (1961) also found in London. The effects of differences in land use and building density are blurred due to the diffusing influence of wind action. Cloudiness is also instrumental in restricting rural cooling by intercepting long-wave radiation from the ground, and thus diminishing any urban-rural temperature difference which might otherwise develop. A further traverse under similar conditions on the night of 28/29 February produced a similarly reduced heat island effect, on this occasion a maximum of $2^{\circ} \mathrm{C}$. Wind speeds over about $5 \mathrm{~m} \mathrm{~s}^{-1}$ and cloud cover above 3 oktas are thus important inhibitors of the development of the Dublin heat island.

\section{Discussion}

Some controversy exists over the role of city size in controlling the maximum urban-rural temperature contrast. In his studies in Leicester and London, Chandler $(1965,1967)$ found similar urban excesses despite the difference in city size. Strong heat islands have been detected around relatively small settlements, even around individual shopping centres (Norwine, 1973). Oke (1973), on the other hand, found a strong relationship with population. The increment of the maximum heat island with population he suggested to be smaller in Europe than North America and capable of being expressed according to the following equation:

$$
\mathrm{T}_{(\mathrm{u}-\mathrm{r}) \max }=2.01 \log \mathrm{P}-4.06
$$

in which $T$ is temperature. $P$ is population and the subscripts $\mathrm{u}$ and $\mathrm{r}$ refer to urban and rural respectively. 


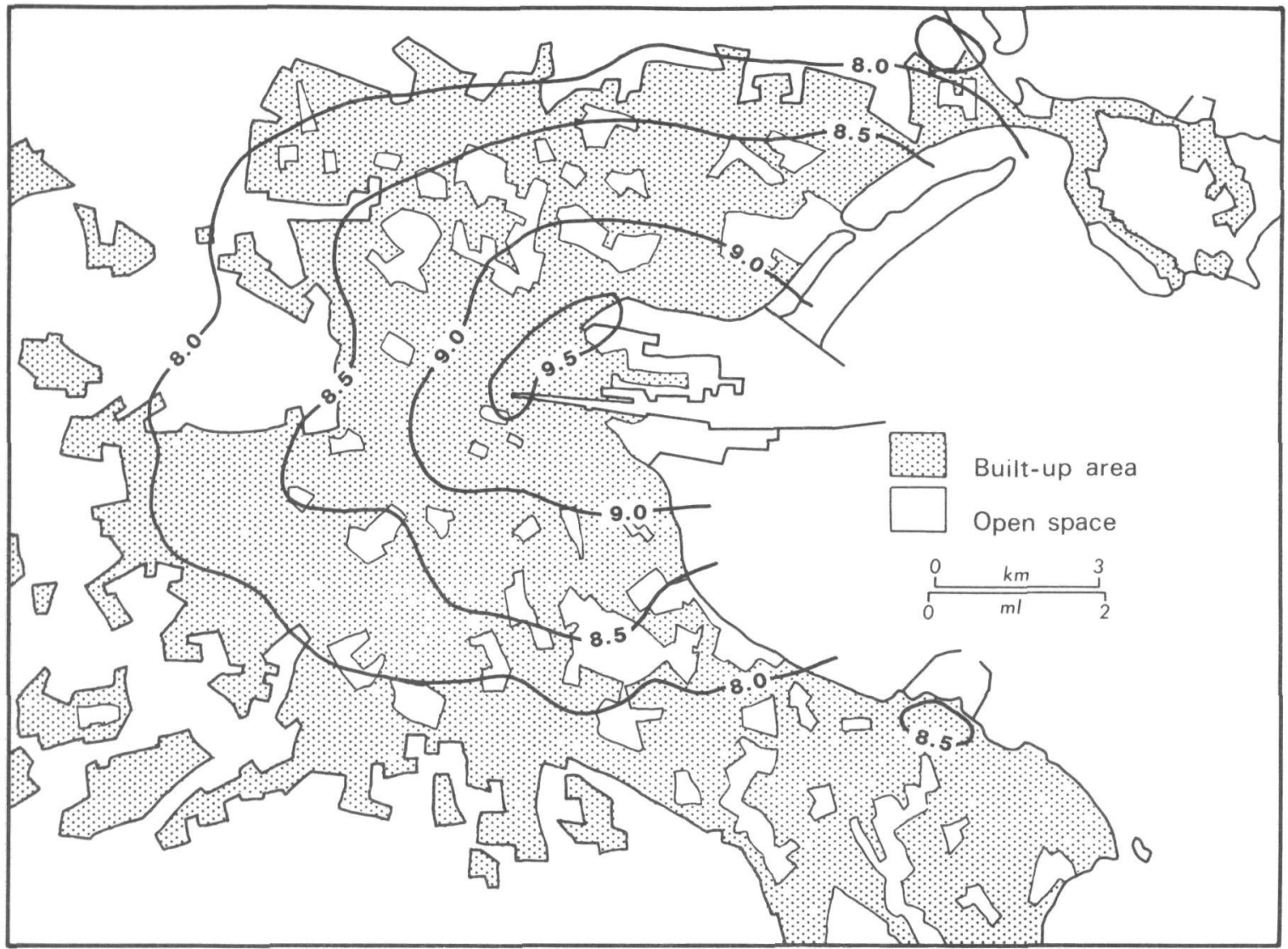

Figure 6 Temperatures in Dublin City 23.00 hrs., 22nd February 1984.

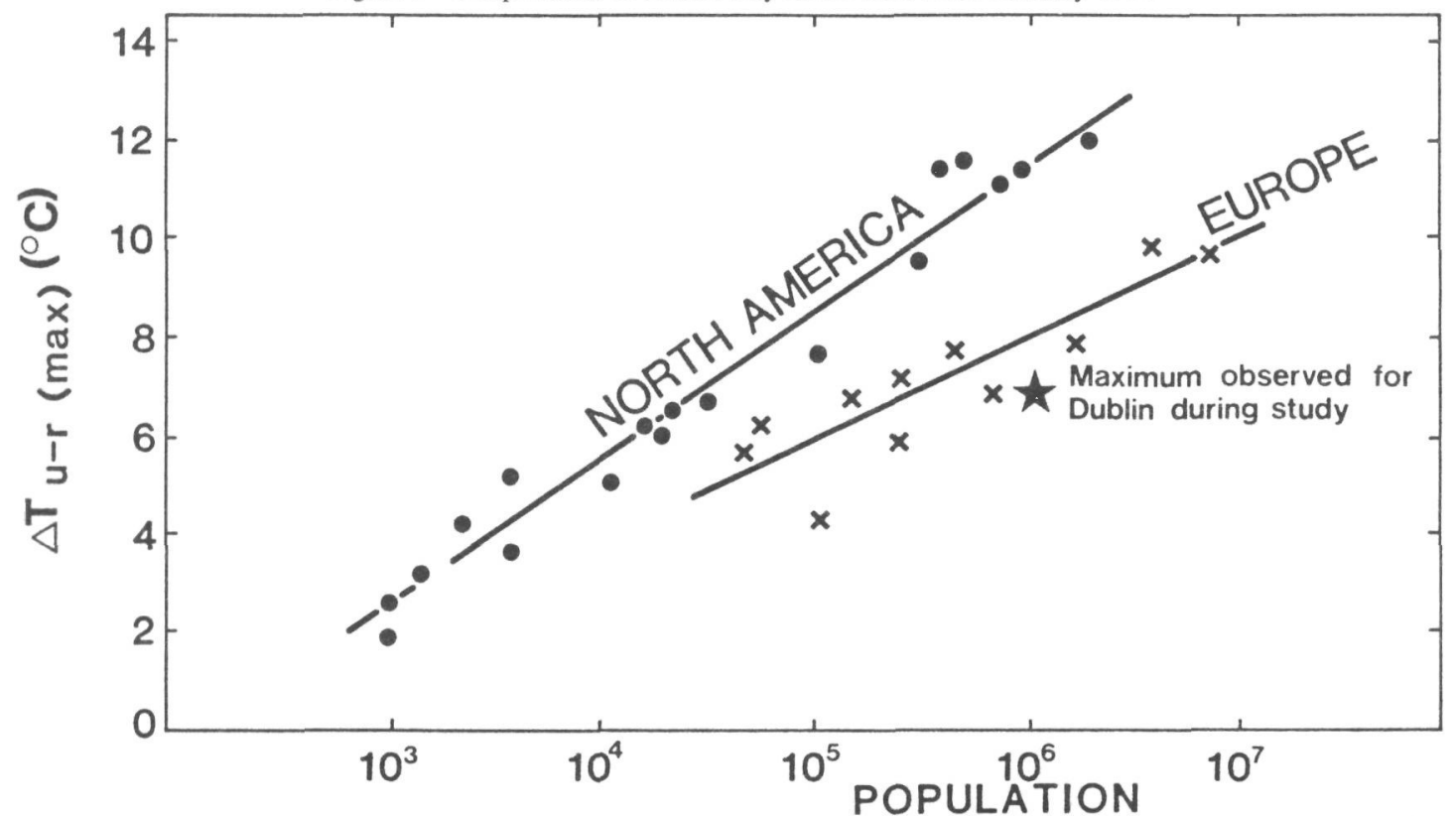

Figure 7 Relationship between maximum observed heat island intensity and population for North American and European Cities (after Oke, 1973) 


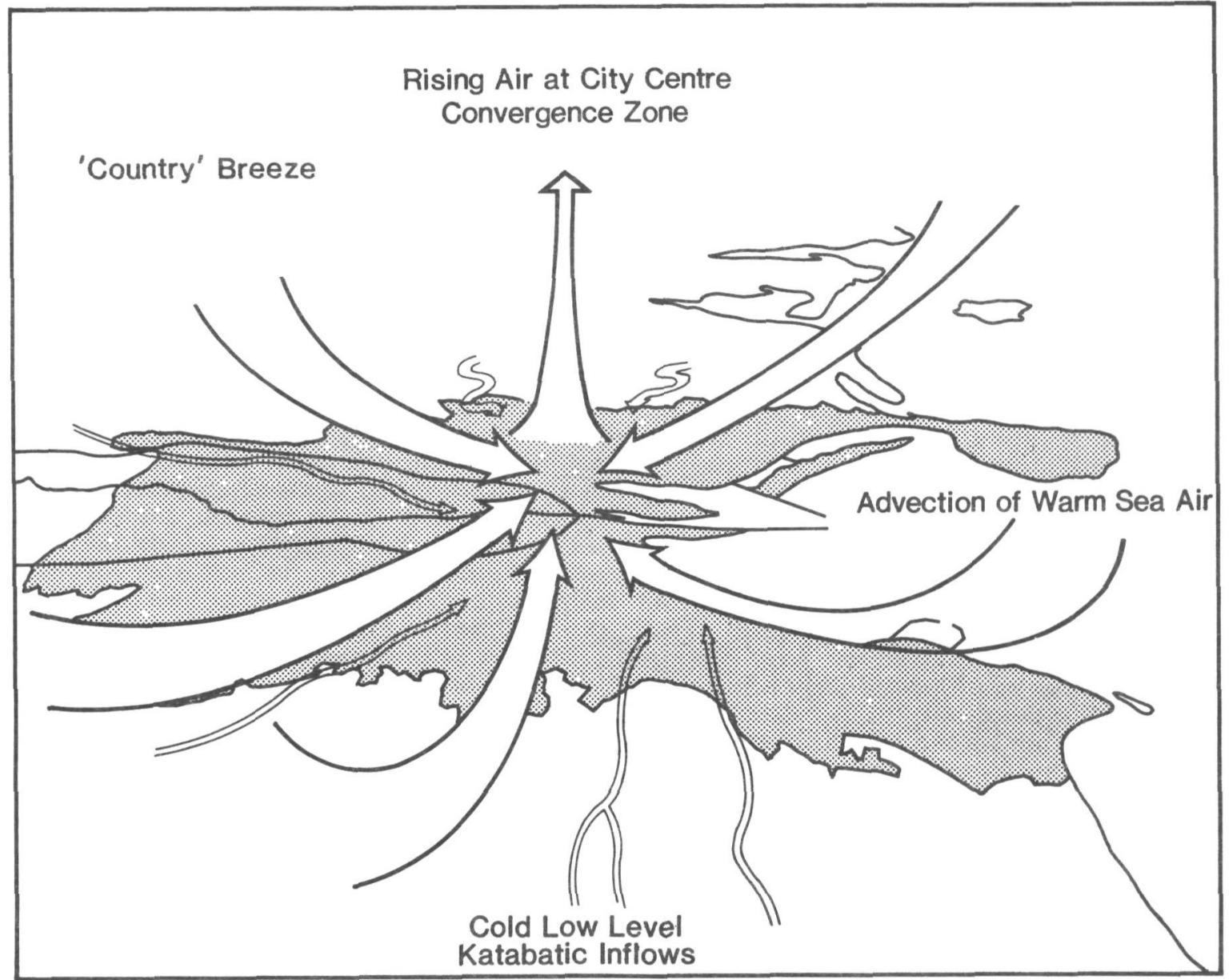

Figure 8 Suggested airflow patterns for Dublin city during nights with good heat island development.

The maximum intensity observed during this study was $6.5^{\circ} \mathrm{C}$. Dublin thus appears to fit reasonably well into the European relationship suggested by Oke (Fig. 7), with a maximum intensity of $8^{\circ} \mathrm{C}$ probably measurable with clear skies and a more lengthy time period of analysis.

City size is certainly important in its control on the critical wind speed necessary for the elimination of the heat island. This varies from city to city and Oke and Hannell (1970) place the threshold (U) at:

$$
\mathrm{U}=3.4 \log \mathrm{P}-11.6
$$

This would imply a value of $8.8 \mathrm{~m} \mathrm{~s}^{-1}$ for Dublin. The Dublin data suggest the heat island is in fact destroyed at slightly lower wind speeds than this, though other factors such as cloud cover may also need to be considered.

It is reasonable to hypothesise that the heat island which creates an unstable vertical lapse in temperature, may induce a rising air current at its centre. A tendency for a low level concentric convergence of air towards the city centre may be a consequence of this, and, in fact, such centripetal urban air flows have been reported from Asahikawa, Japan, (Okita, 1960), Manhattan (Bornstein and Johnson, 1977) and St. Louis (Vukovich et al., 1979). Clearly, the Dublin heat island shows the effect of fairly active mesoscale air movements; the heat island circulation being reinforced by katabatic flows from the Wicklow Mountains in particular. Uplift is also strong enough to draw in relatively warm marine air from Dublin Bay along the eastern fringe of the urban area. Suggested nocturnal circulation features for the city are shown in Figure 8.

The effect of this circulation pattern is highly significant for air pollution diffusion. Eighty per cent of smoke emissions in the city are of domestic origin, principally from the residential areas surrounding the city centre. In such areas, annual emissions are characteristically $125-250$ tonnes $\mathrm{km}_{-2}$ (Bailey, 1984). Yet the highest annual average concentrations of both smoke and sulphur dioxide are arranged concentrically around the commercial core of the city centre. 
Obviously, a transport of pollutants into the central area is occurring. Nights with good heat island conditions are also nights with high pollutant emissions, and it may be suggested that the mesoscale circulations hypothesised here are instrumental in the relocation of Dublin's urban air pollution load. A knowledge of the circulation features of the Dublin urban heat island is thus essential for any urban air pollution model. Indeed, as Bornstein and Johnson (1977) suggest, any urban air pollution model based only on airport data will produce erroneous results.

The significance of substantial intra-urban temperature variation for energy demand management has already been hinted at, However, the existence of the urban heat island also has implications for energy consumption for space heating purposes. Heating degree days (accumulated temperatures below $15.5^{\circ} \mathrm{C}$ ) for Merrion Square (city centre) are typically some 261 less than at Dublin Airport, because of the relative warmth of the urban area (Hargy, 1986). This is an amount equivalent to having one less winter month's heating needs. Energy demand for space heating within Dublin is thus reduced by a substantial quantity as a direct consequence of its urban climatic modification.

\section{Conclusion}

This study has revealed substantially increased nocturnal temperatures in Dublin city during winter nights with light winds and clear skies. However, the classic model of urban heat island behaviour seems complicated by the city's coastal location and by adjacent upland areas. These appear to be responsible for bringing both cold rural and warm oceanic air into the urban area by means of low level flows, probably enhanced by the centripetal circulation induced by the heat island itself. The heat island is thus affected by three local winds: 'country' breezes, sea breezes, and katabatic circulations. However, further study of these flows is clearly required to establish better their characteristics and behaviour under different meteorological conditions.

Further study is also required of the vertical extent of the urban warmth, and the relationship of the adjacent, rural, surface-based temperature inversion. Variations in the vertical extent of the urban boundary layer can be expected to be a significant control on air pollutant diffusion within Dublin city.

Finally, on a more practical note, some account of the heat island phenomenon should now be incorporated into the forecasting of nocturnal minima in the urban area. Substantial economic advantages can accrue to local authorities, for example, from successful forecasting of road surface temperatures in urban areas, in terms of savings in gritting and salting during winter nights. (Twelve million tonnes of salt are applied annually to North American roads (Thornes, 1986)). Some improvement in when and where gritting is necessary in Dublin should also be possible with elucidation of its heat island phenomenon.

\section{References}

BAILEY, M. (1984) Air Quality in Ireland: the present position. An Foras Forbartha, Dublin

BARRING, L., MATTISON, J. and LINDQUIST, S. (1985). Canyon geometry, street temperatures and urban heat island in Malmo, Sweden, Journal of Climatology, 5, 433-444.

BENNETT, M. and SAAB, A. E. (1982) Modelling of the urban heat island and of its interaction with pollutant dispersal, Atmospheric Environment 16, 1797-1822.

BORNSTEIN, R. D. (1968) Observations of the urban heat-island effect in New York, Journal of Applied Meteorology, 7, 575-582.

BORNSTEIN, R. D. and JOHNSON, D.S. (1977) Urban-rural wind velocity differences, Atmospheric Environment, 11, 597-604.

CHANDLER, T. J. (1981) The changing form of London's heat-island, Geography 46, 295-307.

CHANDLER T. J. (1965) The Climate of London. Hutchinson, London, $292 \mathrm{pp}$.

CHANDLER, T. J. (1967) Night-time temperatures in relation to Leicester's urban form, Meteorological Magazine 96, 244-250.

CHANDLER, T. J. (1976) Urban climatology and its relevance to urban design, World Meteorological Organisation Technical Note 149, 61 pp., Geneva.

CHANDLER, T. J. (1978) The Man-Modified Climate of Towns. In, Lenihan, J. and Fletcher, W. The Built Environment, Blackie, Glasgow, 1-25.

GARNETT, A. and BACH, W. (1965) An estimation of the ratio of artificial heat generation to natural radiation heat in Sheffield, Monthly Weather Review 93, 383-385.

HARGY, V. (1986) The construction and use of a digital map for displaying variation of accumulated temperature in Ireland. Paper delivered to the Conference of Irish Geographers, 15-17th May, University College, Cork.

HOWARD, L. (1833) Climate of London Deduced from Meteorological Observations (3rd Ed.), Harvey and Darton. London.

HUFTY, A. (1970) Les conditions de ravonnement en ville. World Meteorological Organisation Technical Note 108, 65-69, Geneva.

JENKINS, I. (1969) Increase in averages of sunshine in central London, Weather, 24, 52-54.

LANDSBERG, H. E. (1981) The Urban Climate, Academic Press, New York, $276 \mathrm{pp}$.

METEOROLOGICAL SERVICE (1983) The Climate of Dublin, Meteorological Service, Dublin, $146 \mathrm{pp}$.

NAPPER, N. J., TYSON, P. D., OWENS, I. F. and HASTIE, W. J. (1981) Modelling the winter urban heat island over Christchurch, New Zealand, Journal of Applied Meteorology 20, 365-376.

NKEMDIRIM, L., C. LUNN, G. R. and ROWE, R. (1975) Pollutant concentration and stratification in urban heat island. Water, Air and Soil Pollution 4, 99-112.

NORWINE, J. R. (1973) Heat island properties of an enclosed multilevel suburban shopping center, Bulletin of the American Meteorological Society 54, 637-641.

OKE, T. R. (1973) City size and the urban heat island, Atmospheric Environment 7, 769-779

OKE, T. R. (1978) Boundary Laver Climates, Methuen, London, $372 \mathrm{pp}$

OKE, T. R. and HANNELL, F. G. (1970) The form of the urban heat island in Hamilton, Canada, World Meteorological Organisation, Technical Note 108, 113-126, Geneva.

OKE, T. R. and MAXWELL, G. B. (1975) Urban heat island dynamics in Montreal and Vancouver, Atmospheric Environment 9, 191-200.

OKITA, T. (1960) Estimation of direction of air flow from observation of rime ice, Journal of the Meteorological Society of Japan II, 38(4), 207-209.

PENMAN, H. L. and LONG, I. (1949) A portable thermistor bridge for micrometeorology among growing crops, Rothamstead Experimental Station, Harpenden.

RENOU, E. (1855) Instructions meteorologiques, Annuaire Soc. Meteorol. de France 3(1), 73-160. 
TERJL NG. W. H. (1970) Urban energy balance climatology: a prelımmary investigation of the city-man system in downtown Los Angeles. Geographical Review 60, 31-53.

THORNES, J. E. (1986) Snow and ice control in North America, Highuavis Meteorology No. 2.

VENKATRAM A and VISKANTA, R. (1976) The contribution of pollutants to the urban heat-island and cross-over effects of elevated pollutant layers on mixed layer growth. Third Simposium on Atmospheric Turbidity, Diffusion and Air Quality. American Meteorological Society, Rayleigh.

VUKOVICH, F. M., KING, W. J., DUNN III, J W. and WORTH, J B. (1979) Observations and simulations of the diurnal variation of the urban heat island circulation and associated variations of the ozone distribution: a case study, Journal of Applied Meteorology 18. 836-854. 